\title{
THERMAL PERFORMANCE COMPARISON ON FLOORING MATERIALS
}

\author{
GALABADA. G.H ${ }^{1}$, DHARMARATNE P. D², GALKANDA. H. ${ }^{3}$ \& HALWATURA. R.U ${ }^{4}$ \\ 1,2,3,4University of Moratuwa, Moratuwa, Sri Lanka \\ 1hyasasiri@yahoo.com, ${ }^{2}$ makway.cons@gmail.com , ${ }^{3}$ himahansi.galkanda@gmail.com, ${ }^{4}$ rangikauh@gmail.com
}

\begin{abstract}
New building materials and technologies that provide thermal comfort are expected to gain popularity in the recent past. Hence, efforts to incorporate new building material solutions are needed to protect potential populations from the threats of thermal stress that cause an increase in temperatures due to climate change. The earth is identified as the most effective building material to improve the thermal comfortability inside the building. Among several building construction materials, the flooring material provides a more effective role with respect to thermal comfort in a building. This paper present the evaluation and comparison work carried out to investigate the thermal performance of newly invented soil based flooring material with other common floorings in Sri Lanka. Temperature measurements were taken on the top surface of flooring materials and were compared the surface temperature of each other and indoor air temperature. The results reveal that the soil floor shows a lesser temperature at a significant level than the other floorings. Hence, it can be proved that the building construction materials play an important role and earth is the best sustainable material with respect to the indoor thermal comfortability thus, end-user.
\end{abstract}

Keywords: Flooring materials, thermal comfortability, tropical climate, sustainable materials

\section{Introduction}

Primary energy demand in the world has increased drastically in recent decades. Therefore, to the directive for energy efficiency in the built environment, the building sector must decrease its use of energy.In order to meet these targets, many different activities must strive towards the same goal. Buildings are major energy consumers, particularly in counties with extreme climatic condition consumig a significant amount of energy to heat and cool. For recent decades requirement of air conditioning units have increased, to offset the demands and offer a comfortable interior thermal environment (Latha, Darshana and Venugopal, 2015). Although there are many ways to minimize the heat and air conditioning load in buildings, one of the most critical way is carefully planing and selection of the building envelope. However, many factors are affected to the thermal comfort and humen helth such as air temperature, radiant temperature, humidity, air circulation, metabolic rate or human activity, clothes etc (Epstein and Moran, 2006), (Park and Nagy, 2018b).

Heat stress is a greater challenge in tropical and warmer climates in "terms of thermal comfort and heat-related deaths and illnesses". Therefore, the effects of hot working conditions on the working community have been recorded in various research around the world (Latha, Darshana and Venugopal, 2015). (Nasrollahi, Knight and Jones, 2008). However, many workplaces have mounted mechanical equipment such as air conditioners, fans, and different types of cooling devices to counterbalance the hot working atmosphere and give thermal relief to staff. These devices are energy-consuming, expensive to repair, and operate solely on electricity(Nasrollahi, Knight and Jones, 2008).

Thermal discomfort can be caused by buildings on their own. If this is not addressed during the design phase, the problem of thermal comfort may become expensive to address afterward. A positive approach to energy efficiency and thermal comfort, is the materials chosen to build the structures during the development phase. Tthe use of environmentally friendly and low thermally conductive building materials for living spaces/workplaces will give a long-term solution to the issue of heat stress caused by 
environmental change. However, is yet to solve. (Djongyang, Tchinda and Njomo, 2010).

Further, the thought of green buildings has arisen in recent years, with the primary goal of using environmentally sustainable materials and reducing resource consumption, reducing electricity demand. Traditional expertise in the use of environmentally friendly and thermally tolerant construction materials has been passed down through generations in developed countries and tropical regions(Kumar and P Singh, 2013).

Minimizing the cooling demand of the living spaces is one way to gain thermal comfort while reducing energy consumption. The use of construction materials as a passive strategy in tropical countries with limited resources and energy supply would be an inexpensive and simple way to monitor while increasing thermal comfort. To achieve thermal comfort, several materials with passive cooling properties may be used. This may be an adaptation technique that provides a long-term approach to the problem of rising temperatures and their effect on the living spaces' thermal comfort.

Various researchers have suggested that the thermal output of advanced materials plays a key role in energy conservation and thermal comfort. Therefore, to achieve the required thermal comfort without losing structural stability, a mixture of natural and synthetic construction materials is frequently used. However, when changing the composition and combining the natural and synthetic materials, it should be taken to consideration that the applications as well as the weather conditions in order to ensure optimum thermal comfort(Shooshtarian et al., 2020). The interior temperature, and the thermal comfort of the building's occupants, is also affected by mutual radiation between the wall and the ceiling(Latha, Darshana and Venugopal, 2015). Natural construction materials have been used from the anciant time, and building materials manufactured with natural ingredients have range of benefits. In fact, the thermal conductivities of a wide variety of natural materials are ideal for use in buildings to provide optimum thermal comfort(Kumar and P Singh, 2013). The thermophysical properties of construction materials, building alignment, airflow, usage of building, and the combination of modern and passive energy conservation technology all affect a building's thermal comfort. (Lucas et al., 2002). However, there are few drawbacks in today's built world such as load-bearing capability and longevity.

Traditional materials have greater thermal conductivities and diffusivities than modern materials, resulting in inefficient and unpleasant heat transport (Kumar and P Singh, 2013). "Bamboo, timber, grass, linoleum, crushed earth block, rammed earth, cement, vermiculite, flax linen, sisal, seagrass, cork, extended clay grains, coconut, wood fiber plates," and other eco-friendly construction materials are all renewable materials and reduce energy consumption inside buildings (De Luca, Carbone and Nagy, 2017) (Farhat, Ghaddar and Ghali, 2014). (Denisselle and Doubrovsky, 1992). Wood and timber are considered to be strong thermal insulators and are ideal for a number of applications such as windows, doors, roofing, and flooring(Gezer, 2003). Wood's thermal properties are a result of moisture content and wood type since it is a hygroscopic fiber. (Latha, Darshana and Venugopal, 2015). Straw has been used as a building material for many years because it is biodegradable and has no environmental impact. In fact, straw is a thermally tolerant fiber with a thermal resistance rating of 6.51 to $7.82 \mathrm{~W} / \mathrm{m}^{2} \mathrm{~K}$ for a $55 \mathrm{~cm}$ thick straw bale which can be the most effective insulator (Garas and Allam, 2011). Interestingly, plastered straw-bale construction is used in load-bearing and in-fill straw-bale construction to produce long-lasting, superinsulated buildings that have thermal comfort. In tropical climates, straw-bale buildings perform better thermally than other materials used for walls, but they have inherent drawbacks such as less bulk to retain heat in the building fabric and poor load-bearing properties, rendering them unsuitable for taller structures(Park and Nagy, 2018a).

Bricks are one of the most significant heat-resistant construction components(Gualtieri et al., 2010).. According to studies(Binici et al., 2007) Mudbrick reinforced with fiber (FRB), retains the indoor temperature lower throughout the summer. Buildings constructed with FRB work better thermally and have a cooler indoor atmosphere than those constructed with clay bricks (GOLDEN MAKAKA and EDSON MEYER, 2006). In a simulation conducted by Alahabad et al., it was discovered that native materials have greater thermal properties than typical building materials(Alhaddad and Jun, 2013). Mud concrete (Udawattha, Galabada and Halwatura, 2017),(Galabada, 2016),(Galabada, Rajapaksha and Halwatura, 2020) and mud concrete reinforced with coir(Galabada, Galkanda, et al., 2020) also identified as thermally comfortable construction material in outdoor construction and indoor construction as well.

New building material and technologies that provide energy efficiency and thermal comfort are important requirment to gain popularity. Among many sustainable materials used to improve the thermal 
comfortability inside the building, the earth is identified as the most effective material. Therefore, a considerable amount of research has been carried out to improve the earth as a construction material, which has been utilized from the ancient stage. Among them, the flooring material developed using soil is one of the most significant findings to the current building construction. This flooring was constructed with soil as the main raw material. The extracted soil comprises different compositions (gravel, sand, fine particles) in different percentages. However, to produce soil floor, the extracted soil needs to be developed into required composition percentages. Then this developed soil is to be mixed with the required amount of cement and water to produce the soil concrete. Soil concrete laid on the floor and its top surface is smoothed and waxed for proper appearance(Galabada and Halwatura, 2019) (Galabada, Dharmaratne, et al., 2020). This paper presents the experimental work carried out to evaluate the thermal performance of newly invented soil based flooring material.

\section{Aim and objectives}

The main aim of this study is to compare the thermal performance of newly invented soil flooring material with the available conventional flooring material.

\section{Material and method}

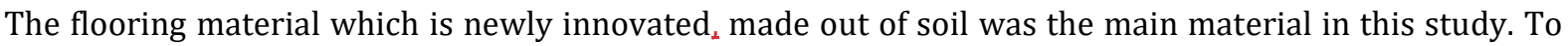
compare the thermal performance with the soil flooring, two other conventional flooring were selected. The flooring materials currently used in Sri Lanka are ceramic tile, cement rendered floor, wood (Parquet floor), and terrazzo. The flooring material which was used for the measurements in this study was the ceramic tile and cement rendered floor. Because these materials are widely used in Sri Lanka as flooring material. Generally, the typical floor of a house consists of three layers: the finishing layer, the plastering layer (cement mortar) and the structure layer (concrete floor base) in conventional flooring. Ceramic tile and cement rendered floor was constructed accordingly. However, the soil flooring construction is differing from conventional flooring. Therefore, this was performed according to the technique described in related published data(Galabada and Halwatura, 2019),(Galabada, Dharmaratne, et al., 2020).

$6 \mathrm{ft} \times 6 \mathrm{ft}$ floor area was laid with selected floorings at the place where indoor environment conditions are the same. All three floors were constructed in the same colour to avoid the colour effect on the surface temperature.

\subsection{CERAMIC TILE FLOOR}

Ceramic tiles in size $2 \mathrm{ft} \times 2 \mathrm{ft}$ were purchased from the market. The colour of the tile was selected to match the colour of soil floor. The tiles were laid on the leveled concrete floor by applying the cement mortar bedding.

\subsection{CEMENT RENDERED FLOOR}

First, the concrete floor was laid, and then make cement mortar bedding. The cement mix with colour pigment to match the colour of the final finish with the soil flooring colour. Then mix with water to make a cement slurry. The cement slurry was applied on the top of the mortar bed to have a cement rendered floor.

\subsection{SOIL FLOOR}

The soil floor was constructed in a $75 \mathrm{~mm}$ thick soil cement mix. Since, this soil floor is a new technique, the method of construction and material used to this floor was carried out according to the construction technique described in related published data (Galabada and Halwatura, 2019), (Galabada, Dharmaratne, et al., 2020). Figure 1 shows a few steps of soil floor construction.

All the floor samples were left for a week to become uniform condition by removing construction moisture etc., before fixing the data logger for temperature measurements. Then the temperature variation was measured on the floor surface continuously for two weeks period. A data logger shown in Figure 2(a) was used to measure the temperature. The temperature on the floor surface and indoor temperature were measured. Then the temperature variation on the surface was compared. 

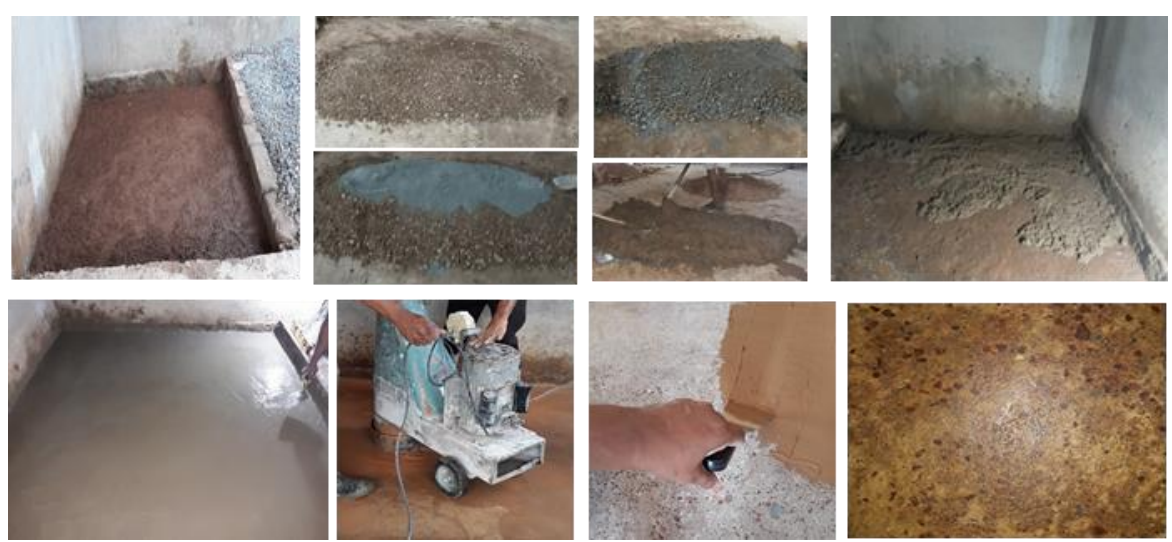

Figure1: Step of soil floor construction

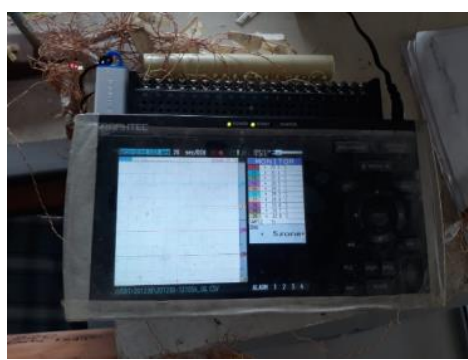

(a)Data logger

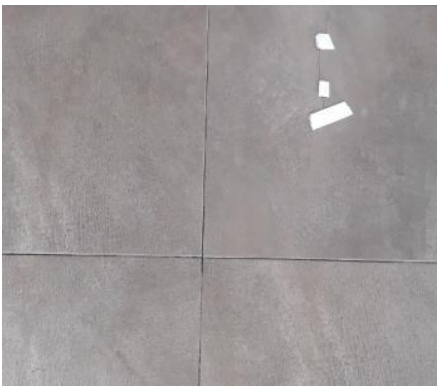

(c) Ceramic tile floor

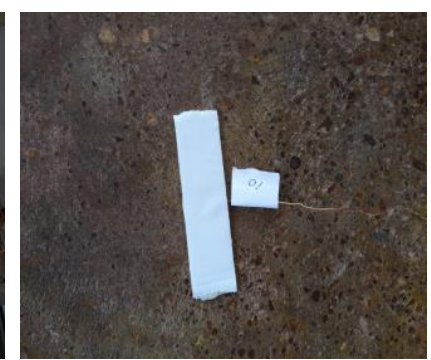

(b) Soil floor

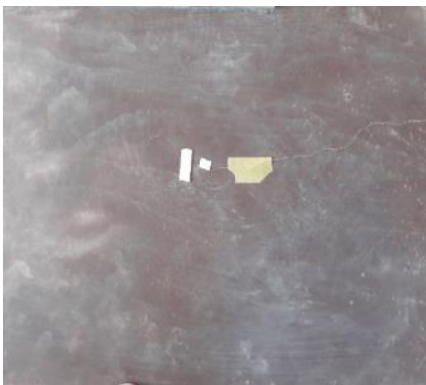

(d) Cement rendered floor

Figure 2, Temperature measurements on floor surfaces

\section{Results and Discussion}

Though the temperature variation was measured throughout a week, the best set of temperatures for 24 hrs was selected for analyses. The average temperature throughout the day ( $24 \mathrm{hrs}$ ) was plotted against time as shown in Figure 3 below. First, compare the temperature variation pattern for conventional floor surface and indoor air temperature. According to the resultant temperature measurements, the ceramic tile floor and cement rendered floor show the same variation pattern throughout the day. Comparing the indoor air temperature, during the morning hours $(1.00 \mathrm{am}-11.00 \mathrm{am})$ the indoor air temperature kept higher than the floor surface. During midday time till $3.00 \mathrm{pm}$ the floor surface and indoor air temperature became same. Hereafter, during night time ceramic tile floor surface and indoor air temperature kept as same while the cement rendered floor surface became lesser than these two. Though the surface temperature shows differences, these differences are less than $1^{\circ} \mathrm{C}$.

Then temperature variation on soil floor compares with the other floors. It shows that this variation is lesser than the other floor surfaces and also indoor air at a significant level. The maximum indoor air temperature was observed at $15-16 \mathrm{hr}$ and it was $28^{\circ} \mathrm{C}$ and at that time the temperatures were $27^{\circ} \mathrm{C}, 27.8^{\circ} \mathrm{C}, 27.8^{\circ} \mathrm{C}$ on soil floor, cement rendered floor, and ceramic tile floor respectively. The results showed that the temperature on the soil floor was $1^{\circ} \mathrm{C}$ lesser than that of other floor surfaces as well as 
indoor air temperature. Further, it could be seen that throughout the day the soil floor surface temperature showed a lower value than other surface and indoor air temperatures as well in a significant amount.

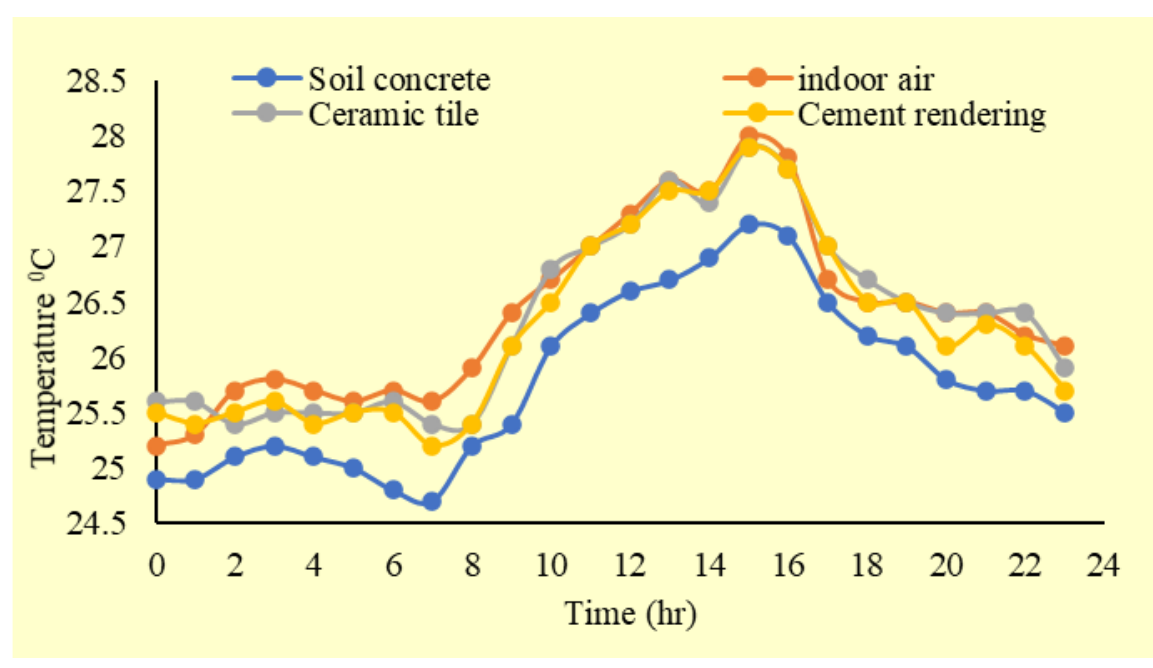

Figure 3, Temperature variation pattern on floor surfaces

\section{Conclusions}

In this study, the thermal performance of the newly invented soil floor was compared with the other two flooring materials which are commonly used in Sri Lanka. Thermal performance comparison results show that the temperature of the soil floor was lesser than the temperature of other floor surfaces which were selected and the temperature of the indoor air in a considerable amount. Therefore, it can be concluded that soil flooring is one of the good innovations for the building construction industry, especially in countries with a tropical climates. Further, with these results, it is proved that the building construction materials play an important role in indoor thermal comfortability. Therefore, it is obvious that newly innovated soil floor can be used to keep indoor thermal comfortability and save energy use for air condition too.

\section{Acknowledgements}

The authors would like specially acknowledged to support given by Mr. H.T.R.M. Thanthirige, (Technical officer of Building Materials Laboratory), Mr. D.M.N.L Dissanayaka, (Technical officer of Structural Testing Laboratory), Mrs.W.B.U. Rukma, (Technical Officer of Construction management division) and other supporting staff in these laboratories, Department of Civil Engineering, University of Moratuwa, Sri Lanka.

\section{References}

Alhaddad, M. A. and Jun, Z. T. (2013) 'A comparative study of the thermal comfort of different building materials in SANA'A', American Journal of engineering and applied sciences, 6(1), pp. 20-24.

Binici, H. et al. (2007) 'Thermal isolation and mechanical properties of fibre reinforced mud bricks as wall materials', Construction and Building Materials, 21(4), pp. 901-906. doi: 10.1016/j.conbuildmat.2005.11.004.

De Luca, P., Carbone, I. and Nagy, J. (2017) 'Green building materials: A review of state of the art studies of innovative materials', Journal of Green Building, 12, pp. 141-161. doi: 10.3992/1943-4618.12.4.141.

Denisselle, A. and Doubrovsky, G. (1992) 'Material in the form of a plate capable of forming a heat-insulating barrier, fire-protection wall including this material, and casing including such a wall', FR2672961, Institut National de la Propriete Industrielle, Paris.

Djongyang, N., Tchinda, R. and Njomo, D. (2010) 'Thermal comfort: A review paper', Renewable and Sustainable Energy Reviews, 14(9), pp. 2626-2640. doi: 10.1016/j.rser.2010.07.040.

Epstein, Y. and Moran, D. S. (2006) 'Thermal comfort and the heat stress indices', Industrial health, 44(3), pp. 388398.

Farhat, R., Ghaddar, N. K. and Ghali, K. (2014) 'Investing in PV systems utilizing savings from building envelop replacement by sustainable local material: a case study in lebanese inland region', International Journal of Energy Economics and Policy, 4(4), p. 554.

Galabada, G. H. (2016) 'Mud concrete paving block for pedestrian pavements in tropical climatic conditions'. Available at: http://dl.lib.mrt.ac.lk/handle/123/12524 (Accessed: 16 December 2020). 
Galabada, G. H., Rajapaksha, M. and Halwatura, R. (2020) ‘Paving Materials for Urban Heat Island Mitigation in Tropics; A Comparative Study on Mud Concrete Paving', 9(3), p. 9.

Galabada, H., Galkanda, H., et al. (2020) 'Investigation of Mechanical Properties of Mud Concrete with Coconut Fiber Reinforcement', in 2020 Moratuwa Engineering Research Conference (MERCon). 2020 Moratuwa Engineering Research Conference (MERCon), pp. 102-106. doi: 10.1109/MERCon50084.2020.9185220.

Galabada, H., Dharmaratne, P. D., et al. (2020) 'Soil as an innovative sustainable flooring material', in 2020 From Innovation to Impact (FITI). 2020 From Innovation to Impact (FITI), pp. 1-6. doi: 10.1109/FITI52050.2020.9424881.

Galabada, H. and Halwatura, R. U. (2019) 'A preliminary study on the use of soil as a floor finishing material', in 2019 From Innovation to Impact (FITI). 2019 From Innovation to Impact (FITI), pp. 1-4. doi: 10.1109/FITI49428.2019.9037635.

Garas, G. and Allam, M. (2011) 'Thermal performance of plastered rice straw bales and walls: a case study', International Journal of Sustainable Development and Planning, 6(2), pp. 226-237. doi: 10.2495/SDP-V6-N2 226-237.

Gezer, N. A. (2003) The effects of construction materials on thermal comfort in residential buildings. Master's Thesis.

GOLDEN MAKAKA and EDSON MEYER (2006) 'Temperature Stability of Traditional and Low-cost Modern Housing in the Eastern Cape, South Africa - Golden Makaka, Edson Meyer, 2006', Journal of BUILDING PHYSICS, 30(1), pp. 71-86.

Gualtieri, M. L. et al. (2010) 'Thermal conductivity of fired clays: Effects of mineralogical and physical properties of the raw materials', Applied Clay Science, 49(3), pp. 269-275. doi: 10.1016/j.clay.2010.06.002.

Kumar, A. and P Singh, O. (2013) 'Advances in the building materials for thermal comfort and energy saving', Recent Patents on Engineering, 7(3), pp. 220-232.

Latha, P. K., Darshana, Y. and Venugopal, V. (2015) 'Role of building material in thermal comfort in tropical climates A review', Journal of Building Engineering, 3, pp. 104-113. doi: 10.1016/j.jobe.2015.06.003.

Lucas, F. et al. (2002) 'Study of moisture in buildings for hot humid climates', Energy and Buildings, 34(4), pp. 345355. doi: 10.1016/S0378-7788(01)00115-3.

Nasrollahi, N., Knight, I. and Jones, P. (2008) 'Workplace satisfaction and thermal comfort in air conditioned office buildings: Findings from a summer survey and field experiments in Iran', Indoor and Built Environment, 17(1), pp. 69-79.

Park, J. Y. and Nagy, Z. (2018a) 'Comprehensive analysis of the relationship between thermal comfort and building control research - A data-driven literature review', Renewable and Sustainable Energy Reviews, 82, pp. 26642679. doi: 10.1016/j.rser.2017.09.102.

Park, J. Y. and Nagy, Z. (2018b) 'Comprehensive analysis of the relationship between thermal comfort and building control research-A data-driven literature review', Renewable and Sustainable Energy Reviews, 82, pp. 26642679.

Shooshtarian, S. et al. (2020) 'Using Recycled Construction and Demolition Waste Products: A Review of Stakeholders' Perceptions, Decisions, and Motivations', Recycling, 5(4), p. 31. doi: 10.3390/recycling5040031.

Udawattha, C., Galabada, H. and Halwatura, R. (2017) 'Mud concrete paving block for pedestrian pavements', Case Studies in Construction Materials, 7, pp. 249-262. doi: 10.1016/j.cscm.2017.08.005. 